adequate and the average number of articles per issue over the first year was seven. In that year, 72 manuscripts were received, 25 of which were rejected outright; most of the accepted manuscripts required revision. So it seems that the editorial board is attempting to promote a good-quality yet focused journal. The fact that more than two-thirds of the papers were reviewed within two weeks will help to continue to attract research articles of a high standard. On the basis of its good start, and blend of basic and clinical articles, Melanoma Research has an excellent chance of survival.

David A. Cheresh is in the Department of Immunology, Scripps Research Institute, 10666 N. Torrey Pines Road, La Jolla, California 92037, USA.

\section{Controversial issues}

\section{J. Kinlen}

European Journal of Cancer Prevention. Editors M. J. Hill and A. Giacosa. Rapid Communications of Oxford. 6/yr. £167, $\$ 299$.

THIS is the second journal on cancer epidemiology, launched only a year after Cancer Causes and Control from the same publisher (reviewed in last year's New Journals issue (Nature 353, 467; 1991)). Its stated aims are to fill a gap in the periodical market on both the specialized subject of metabolic epidemiology and the broader field of cancer prevention, which has resulted in many relevant papers being "lost to the scientific world". Such a gap may exist for the first subject, but the second is covered by, for example, the publisher's other recent journal. The latest journal is also the organ of the European Cancer Prevention Organisation, which has organized several meetings over the past 12 years. It includes papers presented at some of these meetings and reports of studies sponsored by the organization (one having the engaging title "ECPEURONUT-IM Study").

In the first four issues (up to June 1992), about two-thirds of papers concerned gastrointestinal cancers. But for other malignancies, a question of editorial balance arises - in the second issue, in an article entitled "Controversy", the proposition is set up for debate that work on the role of human viruses is "largely wasted" because there is "still little firm evidence for such a role". This is hardly a serious scientific proposition. Indeed, a feature of recent work in cancer aetiology is the mounting evi-

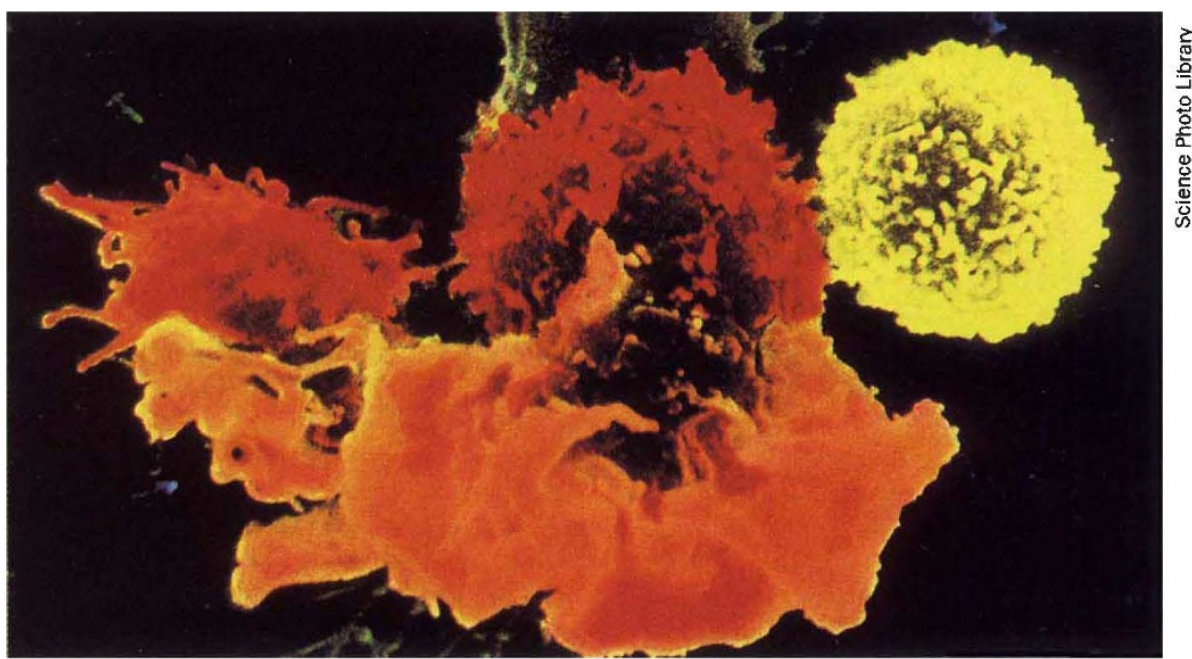

False colour SEM of a lymphoklne-actlvated natural kIller cell (yellow) engaging a cancer cell (red) $(\times 7,770)$.

dence for the role of viruses, the more striking given the disappointment of much 1970 s work. Examples include HTLV-1 in T-cell leukaemia and human papilloma viruses in cervical cancer. Yet in this surprising article, such work is dismissed. Furthermore, in hepatocellular cancer (worldwide, one of the ten commonest cancers), the role of hepatitis B virus is played down because the author regards it as mediated by cirrhosis - as though alcohol could be said to have no role in road accidents because its primary effects are on human behaviour. The editors mention that no one could be found who was interested in responding.

Attractively produced, European Journal of Cancer Prevention reflects current interest in adenocarcinoma of the oesophagus as well as containing some intriguing speculation about the Mediterranean diet and its possible protective effects against cancer. The journal will be of interest to members of the European Cancer Prevention Organisation and to those concerned with the epidemiology of gastrointestinal cancer. But its value to others is less clear.

L. J. Kinlen is in the Cancer Research Campaign Epidemiology Group, University of Oxford, Radcliffe Infirmary, Oxford OX2 GHE, UK.

\title{
Channels of reception
}

\section{Henry R. Bourne}

Receptor. Editor-in-chief Gerald Litwack. Humana. 4/yr. \$150.

SOME of us can remember when receptors existed only as hypotheses, of interest to pharmacologists and a few endocrinologists. Now, hardly any biologist can enter the laboratory without stumbling over a receptor, whether the laboratory studies are on cells, genes, animals, plants, protein structure, development or neurobiology. In every field, receptors abound - hence this new journal.

According to an editorial note in its first issue (late 1990), Receptor seeks to publish papers in "the biochemistry, pharmacology, cell biology, microbiology, molecular biology, and biophysics of every type of receptor". How does this work out in practice? The 15 original reports in the three issues I surveyed described effects of receptor agonists on various events studied in tissue culture cells (seven papers), effects of heat, stress or hormones on receptor abund- ance in cells or animal tissues (three), biochemical characterization of receptors (three) and ligand-binding assays (two). Surprisingly, not one paper evinced more than a passing interest in drugs. In the same 15 papers, eight receptors regulate transcription (receptors for steroids and thyroxine), four are coupled to $G$ proteins, two are receptor tyrosine kinases, one binds prolactin and none is (or regulates) an ion channel.

What about quality? In my opinion, the research reports earn a rating of 'good, but not excellent'. Most present sound, well-executed experiments dealing with more-or-less well understood phenomena, confirming and extending what we already know: solid, reliable papers, with no surprises. The reviews are thorough, well written and of interest to investigators of receptors and other signalling proteins. Like the reports, the reviews reflect on predominant interests of the editor and editorial board: of four reviews in the issues I sampled, three deal with steroid receptors, one 